\title{
Ultrasound diagnosis of macrosomia
}

\author{
Filkaszova A, Chabada J, Stencl P, Drobny J, Sysak R, Urban H, Oravec J, Lamprechtova B, \\ Oroszova V
}

1st Department of Gynaecology and Obstetrics of Comenius University Bratislava, Slovakia. filkaszova@seznam.cz

\begin{abstract}
Over the last two to three decades, there has been a 15-25\% increase in many countries in the number of women giving birth to large infant. Fetal macrosomia is associated with an increased risk of complications both for the mother and the newborn. In current obstetrics, the macrosomic fetus represents a frequent clinical challenge. The early detection and identification of the risks associated with fetal macrosomia is important to managing the pregnancies and at last the timing and mode of delivery. This article provides possibilities of ultrasound diagnosis throughout the pregnancy and investigates the effectiveness of fetal measurements in identifying the large fetus (Tab. 1, Ref. 24). Text in PDF www.elis.sk.

Key words: macrosomia, ultrasound, estimating fetal weight.
\end{abstract}

Macrosomia is arbitrary defined as having a fetal weight of above the 90 th percentile, a birth weight of above $4000 \mathrm{~g}$ or $4500 \mathrm{~g}$, or a birth weight of over +2 standard deviation of the mean birth weight by gestational age. Mean birth weight is described as a function of gestational age. Tab.1 shows potential clinical risk factors for delivering fetus exceeding weight over $4000 \mathrm{~g}$. Several studies from the last half of the 20th century demonstrated consistent results, showing that the 10th percentile of birth weight over the range of gestational ages listed above was 2430-3152 g, whereas the 90th percentile was 3600-4360 g (1). These largefor-gestational-age fetuses (LGA) are at increased risk of perinatal morbidity and mortality such as (a) abnormalities of labor - macrosomic fetuses have a higher incidence of labor abnormalities and instrumental baby deliveries, (b) maternal morbidity-macrosomic fetuses have a two- to threefold increased rate of cesarean delivery or (c) birth injury - the incidence of birth injuries occurring during delivery of a macrosomic infant is much higher with vaginal delivery, in comparison with appropriate-for-gestational-age fetuses (2). For large fetus, the potential complications associated with the delivery include shoulder dystocia, brachial plexus injuries, bony injuries, and intrapartum asphyxia and for mother a birth canal and pelvic floor injuries and postpartum hemorrhage.

\section{Pathophysiology of macrosomia}

The pathophysiology of macrosomia is related to the associated maternal or fetal condition that accounts for its development. In general, poorly controlled diabetes, maternal obesity, and excessive

1st Department of Gynaecology and Obstetrics of Comenius University Bratislava, Slovakia

Address for correspondence: A. Filkaszova, MD, 1st Department of Gynaecology and Obstetrics of Comenius University, Antolska 11, SK-851 07 Bratislava, Slovakia.

Phone: +421.905 .744483$ maternal weight gain are all associated with macrosomia and have intermittent periods of hyperglycemia in common (3). In the second half of pregnancy, increased concentration of human placental lactogen, free and total cortisol, and prolactin combine to produce a modest insulin resistance, which is countered by post-prandial hyperinsulinemia. In those who are unable to mount a hyperinsulinemic response, relative hyperglycemia may develop (gestational diabetes). As glucose crosses the placenta by facilitated diffusion, fetal hyperglycemia results. This, in turn, produces fetal hyperinsulinemia with resultant transfer of glucose into fetal cells leading to fetal macrosomia (4). Fetal hyperinsulinemia causes macrosomia, either directly through its anabolic effect on nutrient uptake and utilization, or indirectly through related peptides such as insulinlike growth factors (the causes and effects of fetal macrosomia in mothers with type 1 diabetes). Hyperglycemia in the fetus results in the stimulation of insulin, insulin-like growth factors, growth hormone, and other growth factors, which, in turn, stimulate fetal growth and deposition of fat and glycogen (5). Insulin, growth hormone $(\mathrm{GH})$, and growth factors (insulin-like growth factors and their binding proteins (IGFBPs) are known to influence fetal growth and also the synthesis/secretion of the recently discovered hormones leptin and ghrelin (6).

Insulin-like growth factor I (IGF-I) is the primary hormone influencing fetal growth in later gestation. The regulation of fetal IGF-I in utero is primarily influenced by placental glucose transfer, which regulates fetal insulin release. Furthermore, insulin has a direct adipogenic effects on the fetus; fetal growth hormone (GH) may also have additional modes of action on fetal growth. Both fetal and maternal IGF-I can influence placental metabolism (7). According to Wiznitzer et al, who studied the relation between fetal macrosomia in offspring of nondiabetic women and the levels of insulin-like growth factors (IGF-I, IGF-II), insulin growth factor binding protein-3 (IGFBP-3) and insulin, in maternal and neonatal compartments, fetal cord blood levels of IGF-I and IGFBP-3 are 
directly correlated with the birth weight of large for gestational age fetuses. These data suggest that the somatotropic axis plays a role in fetal growth. Additionally, insulin growth factor-1 appears to be an in utero growth promoter in the development of fetal macrosomia in infants of nondiabetic women (8).

Fetal growth appears to be regulated by the insulin-like growth factor (IGF) system, although data correlating cord blood measurements of IGFs with birth weight are conflicting.

A potentially important insight into the mechanisms controlling the intrauterine growth is provided by recent studies that modify the traditional idea that white adipose tissue is a simple energy storage tissue, to the idea that it is a highly active endocrine organ secreting a range of hormones of importance in modulating metabolism, energy homeostasis, and growth. Essential elements of this control system are leptin and ghrelin, both signaling nutritional status and energy storage levels to the hypothalamic feeding centers (6).

Leptin also may play a role in enhanced fetal growth; the mechanism is unknown but may involve an interaction with the IGF system. Wiznitzer et al were collecting serum samples from maternal veins and umbilical arteries of 52 consecutive, term, LGA neonates of nondiabetis mothers. Maternal and neonatal serum samples were analyzed for levels of leptin, infulin-like growth factor-I, and insulin by specific radioimmunoassays. There was a statistically significant correlation between umbilical cord leptin and insulin-like growth factor-I levels and birth weight. Data showed that umbilical cord leptin concentration was an independent risk factor for fetal macrosomia. In another study of Lepercq et al, venous cord blood levels of insulin, insulin-like growthfactor I, insulin-like growth factor binding protein 3 and leptin were measured in 28 large-for-gestational-age and 21 appropriate-forgestational-age newborns. Large-for-gestational-age newborns were divided into symmetric and asymmetric subtypes according to the ponderal index. The mean leptin concentrations in cord blood were significantly higher in asymmetric than in symmetric large-for-gestational-age newborns (9).

In Chiesa et al (2008) study, newborns were categorized at birth as appropriate for GA (AGA), large for GA (LGA), and small for GA (SGA). The type of macrosomia was established on the basis of ponderal indes (PI) and Miller charts. LGA newborns whose PI was above the 97 th percentile were classified as having asymmetric macrosomia, and LGA newborns whose PI was between the 10th and 90th percentiles were classified as symmetric. It was proved that both maternal and fetal ghrelin increase with the length of gestation at delivery. Nakara et al. demonstrated that the placenta contributes to the circulating pool of maternal ghrelin during late gestation, and that maternal ghrelin rapidly and easily crosses to the fetus. Also, they showed that while fetal ghrelin originates from the maternal placenta and/or maternal blood, acyl and des-acyl ghrelin are still present in the maternal and fetal circulations during the second half of pregnancy. This data and findings of Chiesa et al indicate a role of maternal and fetal ghrelin in the fetal development (6).

All these studies prove the relationships between metabolic factors, fetal growth, and anthropometry. Maternal and perinatal factors should be taken into account to optimize the understanding of the mechanism, by which endocrine factors may regulate fetal growth.

\section{Estimation of fetal weight}

Obstetric ultrasound has been integrated into the mainstream of obstetric practice in the past quarter century. Ultrasound is used extensively to predict fetal weight and has been presumed to be more accurate than clinical methods for estimating fetal weight. Much effort has generated best-fit fetal biometric algorithms to make birth weight prediction based on obstetric ultrasound measurements. Modern algorithms incorporate standard fetal measurements (e.g. combination of fetal AC, FL, BPD, and HC) (10).

\section{Ultrasound assessment of fetal macrosomia}

\section{Estimated Fetal Weight (EFW):}

- There is a large standard deviation in the mean differences of actual versus estimated fetal weight.

- Sonographic estimated fetal weight is a poor predictor of actual fetal weight. Predictive value is only $64 \%$

- Most formulae for estimated fetal weight overestimate birth weight

\section{Estimated Fetal Weight + Abdominal Circumference (AC).}

- If EFW + AC exceeds the 90th percentile, macrosomia is correctly diagnosed in $88.8 \%$ of fetuses

-It appears that AC growth is accelerated from 32 weeks in a group of large for gestational age (LGA) fetuses

\section{Abdominal Circumference $(A C)$ :}

- Grows at a rate of $\pm 1.2 \mathrm{~cm} /$ week is an optimal cut-off point for detecting LGA infants. Sensitivity $=83.8 \%$, specificity $=$ $85.4 \%$, positive predictive value $=78.8 \%$ and negative predictive value $=89 \%$

- AC of $>35 \mathrm{~cm}$ may identify $>90 \%$ of fetuses with macrosomia that are at risk for shoulder dystocia

- AC minus BPD of $2.5 \mathrm{~cm}$ or more predicted all cases of shoulder dystocia in one series but was not predictive in another series

- AC of $>2$ standard deviations is also a good predictor of LGA infant

\section{FL/AC Ratio:}

Ratio correctly identified $89 \%$ of LGA fetuses compared to $63 \%$ in non-diabetic fetuses

\section{HC/AC Ratio:}

Gestational age dependent (accurate gestational age is essential) $(11,12,13)$.

Apart from these commonly used formulae, other sonographic fetal measurements are used to estimate fetal weight (e.g. crosssectional area of umbilical cord, fetal fat layer or CRL) or even new mathematical formula or GAP method in women with elevated body mass index (BMI). 
Prediction of fetal macrosomia using sonographically measured abdominal subcutaneous tissue thickness

Petrikovsky et al (1997) measured sonographically abdominal subcutaneous tissue thickness in 133 term fetuses. All studied fetuses were delivered within 72 hours after the measurements were taken. One hundred thirteen fetuses were normal size, and 20 were macrosomic. The fetal abdominal subcutaneous tissue thickness ranged between 3 and $18 \mathrm{~mm}$ in all fetuses, with the mean measurement of $8.4 \pm 2.7 \mathrm{~mm}$ (standard deviation). The mean tissue thickness differed significantly between normal and macrosomic fetuses ( $7.0 \mathrm{~mm}$ versus $12.4 \mathrm{~mm}$, respectively; $\mathrm{p}<0.0001)$. There was a significant positive correlation between the abdominal subcutaneous tissue thickness and the birth weight $(\mathrm{r}=0.67, \mathrm{p}<0.0001)$. The negative predictive value for a range of cut-off points between 8 and $13 \mathrm{~mm}$ varied between $84.3 \%$ and $100 \%$ (for prevalence rates of macrosomia of 5-25\%). However, the positive predictive value was less than $50 \%$ for cut-off values below $11 \mathrm{~mm}$ (14). Large cross-sectional area of the umbilical cord as a predictor of fetal macrosomia

was included in the study by Cromi et al (2007) in 1026 patients of $>34$ weeks' gestation, who delivered within 4 weeks of the examination of sonographic measuring of cross-sectional areas of the umbilical cord. The umbilical vessels and the Wharton's jelly were measured in a free loop of the umbilical cord. Fifty-three (5.2 $\%$ ) newborns had a birth weight $>4000 \mathrm{~g}$, and $22(2.1 \%)$ weighed $>4500 \mathrm{~g}$. The proportion of cases with a large umbilical cord was significantly higher in the group of macrosomic compared to nonmacrosomic infants $(54.7 \%$ vs $8.7 \%, \mathrm{p}<0.0001)$. The combination of abdominal circumference $>95$ th percentile and large cord predicted $100 \%$ of macrosomic infants (15).

\section{First trimester prediction of fetal macrosomia}

Hackmon et al (2008) studied the association between fetal biometry in the first or early second trimester and severe macrosomia at delivery in effort to find out if severe macrosomia can be manifested at 11-14 weeks of gestation. They used a case-control study which included 30 term severely macrosomic neonates and 90 appropriate-for-gestational age (AGA) neonates served as controls. The pregnancies, which were dated by an accurate last menstrual period consistent with the crown-rump length (CRL) measurements at the time of screening, early pregnancy CRL or date of fertilization underwent nuchal translucency (NT) screening at 11-14 weeks' gestation. The study analyzed the association between birth weight and the difference between the measured and the expected CRP at the time of NT screening. The difference between measured and expected CRL, expressed both in $\mathrm{mm}$ and in days of gestation, was statistically higher in the severely macrosomic neonates compared to controls (mean, $6.66 \pm 4.78 \mathrm{~mm}$ vs $1.17 \pm 4.6$ $\mathrm{mm}, \mathrm{p}<0.0001$ and $3 \pm 2.2$ days vs $0.5 \pm 2.3$ days, $\mathrm{p}<0.0001$, respectively). Furthermore, there were significant correlations between the extent of macrosomia and the discrepancy between expected and measured fetal size at the time of NT screening $(r=0.47, p<0.01$ and $\mathrm{r}=0.48, \mathrm{p}<0.01$, respectively) (16).
Tab. 1. Clinical risk factors for fetal weight higher than 4000 grams.

\begin{tabular}{lcc}
\hline Risk Factors & $\begin{array}{c}\text { Percent of Patients } \\
\text { with Macrosomic } \\
\text { Fetuses with } \\
\text { Presence of } \\
\text { Risk Factors }\end{array}$ & $\begin{array}{c}\text { Odds Ratio } \\
\text { for Presence of } \\
\text { Risk Factors } \\
\text { Compared with } \\
\text { Controls }\end{array}$ \\
\hline Maternal diabetes mellitus ${ }^{\ddagger}$ & $2-30 \%$ & $1.6-3$ \\
Abnormal 50-g GST $\left(\right.$ without GDM $\left.^{\S}\right)$ & $15-27 \%$ & $1.8-2.1$ \\
Abnormal single 3-h GTT Galue $^{\mathrm{Il}}$ valu & $8-34 \%$ & $1.9-2.4$ \\
Prolonged gestation $(>41 \mathrm{wk})$ & $19-35 \%$ & $5.5-5.9$ \\
Maternal obesity & $16-37 \%$ & $1.7-4.4$ \\
Pregnancy weight gain $>35 \mathrm{lb}$ & $21-56 \%$ & $1.5-2.2$ \\
Maternal height $>5 \mathrm{ft} 3$ in & $20-24 \%$ & $1.5-2$ \\
Maternal age $>35 \mathrm{y}$ & $12-21 \%$ & $1.3-2.3$ \\
Multiparity & $64-93 \%$ & $1.2-1.3$ \\
Male fetal sex & $62-69 \%$ & $1.2-1.4$ \\
White maternal race & $45-94 \%$ & $1.1-2.5$ \\
\hline
\end{tabular}

${ }^{\dagger}$ All classes, including gestational diabetes mellitus; the wide range of values reflects differences among studies in the following: (1) criteria used for screening and diagnosis, (2) prevalence of disease in the populations under study, and (3) success of glucose control during pregnancy, ${ }^{\star} \mathrm{GST}$ - One-hour 50-gram oral glucose screening test, ${ }^{\S} \mathrm{GDM}$ - Gestational diabetes mellitus, "GTT - Three-hour 100-gram oral glucose tolerance test (18)

In another retrospective cohort study of 19377 singleton pregnancies, dated in gestational weeks 16-20 during 6-year period, Thorsell et al (2009) focused on an increased risk of excessive birth weight. When fetuses were $\geq 7$ days larger than expected at dating, compared to the expected size according to last menstrual period, there was a $59 \%$ increase in the risk of birth weight $\geq 4500 \mathrm{~g}$ and a $145 \%$ increase in the risk of birth weight $\geq 5000 \mathrm{~g}$ (odds ratio (OR), 1.59; 95\% CI, 1.12-2.24 and OR, 2.45; 95\% CI, 1.22-4.90, respectively). For a birth weight of $\geq 4000 \mathrm{~g}$, the risk estimate was 1.19 (95\% CI, 0.96-1.47).

These two studies emphasize that fetal size in early pregnancy is not only functional of gestational duration, but also of fetal growth (17).

\section{Macrosomia: a new formula for optimized fetal weight esti- mation}

Hart et al (2010) carried out within 1 week of delivery ultrasound estimations of fetal weight in 424 singleton fetuses with a birth weight of $\geq 4000 \mathrm{~g}$. Exclusion criteria were multiple pregnancy, intrauterine death and major structural or chromosomal anomalies. Regression modeling has been used to derive a prediction formula for birth weight, including such variable parameters as maternal weight, fetal biometric measurements:

$\left(\log _{e} E F W=7.6377445039+0.0002951035 \times\right.$ maternal weight + $0.0003949464 \times$ head circumference $+0.0005241529 \times$ abdominal circumference $+0.0048698624 \times$ femur length)

proved to be superior to established equations, with the smallest mean error (mean $\pm \mathrm{SD},-10 \pm 202 \mathrm{~g}$ ), the smallest mean percentage error (mean $\pm \mathrm{SD},-0.03 \pm 4.6 \%$ ) and the lowest mean absolute percentage error (3.69 (range, $0.05-13.57) \%$ ). With the new formula, $77.9 \%$ of estimates fell within $\pm 5 \%$ of the actual weight at birth, $97.1 \%$ within $\pm 10 \%$, and $100 \%$ within $\pm 15 \%$ and $\pm 20 \%$ (18). 


\section{Prediction accuracy of macrosomia}

The scientific literature confirms that prediction of fetal macrosomia is complicated. Ultrasound has been proposed as a more accurate method of estimation of fetal weight. Unfortunately, the average mean error ranges from 300 to $550 \mathrm{~g}$ (11.6 to $19.4 \mathrm{oz}$ ) (19, 20). Limitations in the sensitivity and specificity of ultrasound have been observed in some cases. Despite these limitations, ultrasound estimation of fetal weight adds little additional useful information to clinicians in predicting macrosomia.

\section{Clinical implication}

Risk factors and biometry in early prenatal care enables us to predict fetal birth macrosomia in some cases only. Usually, acceleration of the fetal growth occurs in last month/weeks of pregnancy. Before achieving the criteria for macrosomia, medical intervention only in cases of fetal pathology (e.g. diabetic fetopathy, fetal malformation) is needed. Once the diagnosis of fetal macrosomia is established, no expectant approach is recommended (21). Elective caesarean section or labor induction is indicated.

\section{Conclusion}

Macrosomia remains a common complication in pregnancy and by delivery; its prediction is insufficient, and there are no reliable interventions to improve outcome in uncomplicated pregnancies (22). What clinicians really want to predict is not macrosomia, per se, but the serious complications that are incorrectly associated with macrosomia, such as brachial plexus injury or shoulder dystocia. These complications, however, are not determined by birth weight alone, but by a complex and poorly understood relationship between fetal and maternal anatomy and other factors $(23,24)$.

\section{References}

1. Amini SB, Catalano PM, Hirsch V, Mann LI. An analysis of birth weight by gestational age using a computerized perinatal data base, 19751992. Obstet Gynecol 1994; 83 (3): 342-352.

2. Rosati P, Exacoustós C, Caruso A, Muncuso S. Ultrasoud diagnosis of fetal macrosomia. Ultrasound Obstet Gynaecol 1992; 2: 23-29.

3. http://emedicine.medscape.com/article/262679-overview\#a0104

4. Turkzadeh H. Foetal Macrosomia (large for gestational age foetus). IJPD 2005; 4 (5): 11-12.

5. Wang HS, Chard T. The role of insulin-like growth factor-I and insulinlike growth factor-binding protein-1 in the control of human fetal growth. J Endocrinol 1992; 132: 11-19.

6. Chiesa C, Osborn JF, Haass C et al. Ghrelin, leptin, IGF-1, IGFBP-3, and insulin concentrations at birth: Is there a relationship with fetal growth and neonatal anthropometry? Clin Chem 2008; 54: 550-558.
7. Gluckman PD, Harding JE. The physiology and pathophysiology of intrauterine growth retardation. Horm Res 1997; 48: 11-16.

8. Wiznitzer A, Reece EA, Homko C et al. Insulin-like growth factors, their binding proteins, and fetal macrosomia in offspring of nondiabetic pregnant women. Am J Perinatol 1998; 15: 23-28.

9. Wiznitzer A, Furman B, Zuili I et al. Cord leptin level and fetal macrosomia. Obstet Gynecol 2000; 96: 707-713.

10. http://emedicine.medscape.com/article/262865-overview

11. Landon MB, Mintz MC, Gabbe SG. Sonographic evaluation of fetal abdominal growth: predictor of the large- for-gestational-age infant in pregnancies complicated by diabetes mellitus. Am J Obstet Gynecol 1989; 160: 115-121.

12. Jazayeri A, Heffron JA, Phillips R, Spellacy WN. Macrosomia prediction using ultrasound fetal circumference of 35 centimeters or more. Obstet Gynecol 1999; 93: 523-526.

13. Jaffee R, The-Hung B (Eds). Textbook of Fetal Ultrasound. London; Parthenon Publishers, 1999: 81-86.

14. Petrikovsky BM, Oleschuk C, Lesser M, Gelertner N, Gross B. Prediction of fetal macrosomia using sonographically measured abdominal subcutaneous tissue thickness. J Clin Ultrasound 1997; 25: 378-382.

15. Cromi A, Ghezzi F, Di Naro E, Siesto G, Bergamini V, Raio L. Large cross-sectional area of the umbilical cord as a predictor of fetal macrosomia. Ultrasound Obstet Gynecol 2007; 30: 861-866.

16. Hackmon R, Le Scale KB, Horani J, Ferber A, Divon MY. Is severe macrosomia manifested at 11-14 weeks of gestation? Ultrasound Obstet Gynecol 2008; 32: 740-743.

17. Thorsell M, Kaijser M, Almström H, Andolf E. Large fetal size in early pregnancy associated with macrosomia. Ultrasound Obstet Gynecol 2010; 35: 390-394.

18. Hart NC, Hilbert A, Meurer B, Schrauder M, Schmid M, Siemer J, Voigt M, Schild RL. Macrosomia: a new formula for optimized fetal weight estimation. Ultrasound Obstet Gynecol 2010; 35: 42-47.

19. Chauhan SP, Lutton PM, Bailey KJ, Guerrieri JP, Morrison JC. Intrapartum clinical, sonographic, and parous patients' estimates of newborn birth weight. Obstet Gynecol 1992; 79: 956-958.

20. Watson WJ, Soisson AP, Harlass FE. Estimated weight of the term fetus. Accuracy of ultrasound vs. clinical examination. J Reprod Med 1988; 33: 369-371.

21. http://www.prolekare.cz/ceska-gynekologie-clanek/doporucenepostupy-v-perinatologii-5435

22. Mark A, Zamorski MD, M.H.S.A., BIGGS WS. Management of suspected fetal macrosomia. Am Farm Physician 2001; 63 (2):302-307.

23. Hall MH. Guessing the weight of the baby. Br J Obstet Gynaecol 1996; 103: 734-736.

24. Baskett TF, Allen AC. Perinatal implications of shoulder dystocia. Obstet Gynecol 1995; 86: 14-17.

Received February 21, 2012. Accepted August 18, 2013. 